\title{
High dietary calcium decreases blood pressure in normotensive rats
}

N. Buassi

\section{Correspondence \\ N. Buassi \\ Departamento de Ciências \\ Fisiológicas \\ Universidade Estadual de Londrina \\ 86051-990 Londrina, PR \\ Brasil}

Research supported by CNPq and CPG-UEL.

Received February 24, 1997

Accepted May 21, 1998
Departamento de Ciências Fisiológicas, Centro de Ciências Biológicas, Universidade Estadual de Londrina, Londrina, PR, Brasil

\section{Abstract}

This study evaluates the influence of different concentrations of calcium on blood pressure of normotensive rats. Four groups of Wistar rats $(\mathrm{A}, \mathrm{B}, \mathrm{C}$ and $\mathrm{D})$ had free access to modified isocaloric and isoproteic diets containing $0.2,0.5,2$ and $4 \mathrm{~g} \%$ calcium as calcium carbonate for a period of 30 days. Systolic and diastolic arterial blood

Key words

- Calcium carbonate

- Arterial blood pressure

- Dietary calcium pressures were monitored in awake rats by the indirect tail cuff method using a Physiograph equipped with transducers and preamplifiers. Body weight and length and food intake were monitored. Under the conditions of the present experiment, the systolic and diastolic arterial blood pressures of group D rats fed a diet containing $4 \mathrm{~g} \%$ calcium were significantly $(\mathrm{P}<0.05)$ lower compared to rats of the other groups.

Debate on the potential role of dietary calcium in the prevention and/or treatment of hypertension has a long history and has been fueled by recent studies reporting relationships among several cations, including calcium, in the physiology of blood pressure regulation (1). An inverse relationship between calcium intake and arterial blood pressure has been shown $(2,3)$, indicating that calcium is important for blood pressure regulation. Animal (4) and human (5) experiments suggest that a low calcium intake contributes to the development of hypertension and calcium may prevent elevations in arterial pressure. Differential effects of calcium supplementation on blood pressure have been observed in normotensive and hypertensive subjects $(5,6)$. Studies of major epidemiologic databases carried out to evaluate the link between diet and hypertension have led to contradictory conclusions. Reduced cal- cium intake was the most consistent factor in hypertensive individuals (2) and calcium intake was inversely correlated with systolic blood pressure, but other studies detected no association between calcium intake and blood pressure $(7,8)$.

The results of animal studies are more consistent in demonstrating a link between dietary calcium and hypertension than observations in human subjects. The effect of calcium supplementation was modest in normotensive animals but had an overall blood pressure-lowering action in several experimental models of hypertension $(9,10)$. The complexity of this subject has made it difficult to draw any definitive conclusions about the role of dietary calcium in the prevention of hypertension (1).

Limited work has been done to determine the long-term effects of dietary calcium supplementation on normotensive animals. The 
objective of the current study was to investigate the effects of diets containing different concentrations of calcium, as calcium carbonate, on the arterial blood pressure of normotensive rats.

Male Wistar rats, Rattus rattus, aged 49 days were used in these experiments. Animals were housed in individual wire mesh cages under conditions of constant temperature of $22 \pm 2^{\circ} \mathrm{C}$ and a normal 12-h light/dark cycle. Thirty-two animals weighing $165 \pm 11$ $\mathrm{g}$ were randomly divided into four groups (A, B, C and D). During the 30-day experimental period, rats had free access to modified diets containing $0.2,0.5,2$ and $4 \mathrm{~g} \%$ calcium, as calcium carbonate. The composition of isocaloric and isoproteic diets are given in Ref. 11. Calcium was provided as carbonate because this form is widely used in calcium supplements (12). Distilled water and diets were offered ad libitum and monitored weekly. Diets were offered and measured in stainless steel cups with inner rings to minimize spillage and animal body weights and lengths were measured weekly.

Systolic and diastolic arterial blood pressures were determined weekly in awake rats by the indirect tail cuff method using a Physiograph (Narco Biosystem, Houston, TX) equipped with transducers and preamplifiers. All measurements were made inside a thermally controlled, ventilated, restraining cage to facilitate recording for small confined, unanesthetized laboratory animals over long periods of time.

Results are reported as means \pm SEM and the statistical significance of differences between group means was assessed by the Tukey test. The values were considered to be significantly different at $\mathrm{P}<0.05$. Data were analyzed using the statistical analysis system (SAS) (13).

In the present study we monitored calcium intake and changes in blood pressure in normotensive Wistar rats fed different levels of calcium in their diets, with other components kept constant. The calcium levels added to the diet were low $(0.2 \mathrm{~g} \%)$, normal $(0.5$ $\mathrm{g} \%)$, moderately high ( $2 \mathrm{~g} \%)$ and high (4 $\mathrm{g} \%)$ (14), with a twenty-fold difference between the highest and lowest concentrations. This difference was planned to maximize the effect of dietary calcium on changes of arterial blood pressure. Diets containing 0.4 to $0.5 \mathrm{~g} \%$ calcium are required to support maximum calcification during growth, but the 0.2 $\mathrm{g} \%$ calcium diet contained the lowest calcium concentration needed to support maximum weight gain in rats (15). The $4 \mathrm{~g} \%$ calcium diet was the highest concentration shown by other investigators to reduce arterial blood pressure in the spontaneously hy-

Table 1 - High dietary calcium decreases arterial blood pressure of normotensive rats fed isoproteic and isocaloric diets containing $0.2,0.5,2.0$ and $4.0 \mathrm{~g} \%$ calcium as calcium carbonate for 30 days ad libitum.

Data are reported as means \pm SEM for 8 rats in each group. $* \mathrm{P}<0.05$ compared to the arterial systolic and diastolic blood pressures of the other groups (Tukey test).

\begin{tabular}{|c|c|c|c|c|c|}
\hline \multirow[t]{2}{*}{ Parameters } & \multicolumn{5}{|c|}{ Dietary calcium (g\%) } \\
\hline & 0.2 & & .5 & 2.0 & 4.0 \\
\hline Systolic pressure $(\mathrm{cmHg})$ & $11.17 \pm 0.73$ & $11.74 \pm$ & \pm 0.98 & $11.46 \pm 0.49$ & $9.69 \pm 1.07^{*}$ \\
\hline Diastolic pressure $(\mathrm{cmHg})$ & $6.17 \pm 0.69$ & $7.93 \pm$ & \pm 0.59 & $7.77 \pm 0.79$ & $5.96 \pm 0.92 *$ \\
\hline Cumulative food intake (g) & $617.0 \pm 11.2$ & $626.0 \pm$ & \pm 36.5 & $625.0 \pm 31.8$ & $635.0 \pm 47.7$ \\
\hline Initial body weight $(\mathrm{g})$ & $166.0 \pm 14.9$ & 167.0 & \pm 11.2 & $165.0 \pm 9.5$ & \pm 9.7 \\
\hline Final body weight (g) & $200.0 \pm 10.9$ & 204.0 & \pm 10.1 & $206.0 \pm 13.3$ & \pm 17.9 \\
\hline Initial body length (cm) & $34.3 \pm 1.5$ & 34.4 & \pm 0.8 & $34.7 \pm 0.9$ & \pm 0.7 \\
\hline Final body length $(\mathrm{cm})$ & $37.6 \pm 0.8$ & 38.7 & \pm 0.6 & $38.3 \pm 0.9$ & \pm 0.9 \\
\hline
\end{tabular}


pertensive rat (16).

Body weight and length and cumulative food intake (Table 1) were the same (ANOVA, P $>0.05$ ) for all the experimental groups. The rats of group D fed a highcalcium diet for 30 days had significantly $(\mathrm{P}<0.05)$ lower systolic and diastolic blood pressures than the other groups. These results are consistent with studies showing supplemental calcium to be associated with a reduction of arterial blood pressure in both normotensive and hypertensive animals (1719). Despite accumulating evidence, the mechanisms by which calcium lowers blood pressure are still unknown. A plausible hypothesis is an impact on free intracellular calcium ion, a significant determinant of blood pressure regulation. The relationship between calcium and hypertension may then involve the energy-dependent gradient between intracellular and extracellular calcium (20).

Both systolic and diastolic arterial blood pressures were significantly influenced by dietary calcium under the conditions of this experiment. Diet is only one of several environmental factors that affect arterial blood pressure and in this case a high dietary calcium concentration led to significantly lower arterial blood pressure. The present data support the view that increases in dietary calcium can have a hypotensive effect on normotensive rats.

\section{References}

1. Hamet P (1995). The evaluation of the scientific evidence for a relationship between calcium and hypertension. J ournal of Nutrition, 125: 311s-400s.

2. McCarron DA, Morris DC, Henry JH \& Santon J L (1984). Blood pressure and nutrient intake in the United States. Science, 224: 1392-1398.

3. Belizan J M, Vilar J, Pineda O, Gonzalez AE, Sainz E, Garrera G \& Sibrian R (1983). Reduction of blood pressure with calcium supplementation in young adults. J ournal of the American Medical Association, 249: 1161-1165.

4. McCarron DA, Lucas PA, Sheidman RJ, LaCour B \& Tilman D (1985). Blood pressure development of the spontaneously hypertensive rat after concurrent manipulations of dietary calcium and sodium. J oumal of Clinical Investigation, 76: 11471154.

5. J ohnson NE, Smith EL \& Freudenhaim J L (1985). Effects on blood pressure of calcium supplementation of women. American J ournal of Clinical Nutrition, 42: 1217.

6. McCarron DA \& Moris DC (1985). Blood pressure responses to oral calcium in persons with mild to moderate hypertension. Annals of Internal Medicine, 103: 68256831.

7. Feinleib M, Lenfant C \& Miller SA (1984). Hypertension and calcium. Science, 226: 384-386.
8. Sempos C, Cooper R, Kovar MG, J ohnson C, Drizd T \& Yetley E (1986). Dietary calcium and blood pressure in National Health and Nutrition Examination Surveys I and II. Hypertension, 8: 1067-1074.

9. Dumas P, Tremblay J \& Hamet P (1994). Stress modulation by electrolytes in salt sensitive spontaneously hypertensive rats. American J oumal of the Medical Sciences, 307 (Suppl 1): S130-S137.

10. Bukoski RD, Xue $\mathrm{H} \&$ McCarron DA (1989). Mesenteric artery contractile properties during dietary calcium manipulation in spontaneously hypertensive and Wistar Kyoto normotensive rats. American J ournal of Hypertension, 2: 440-448.

11. Bogden DJ, Gertner SB, Christakos S, Kemp WF, Yang Z, Katz RS \& Chu C (1992). Dietary calcium modifies concentrations of lead and other metals and renal calbindin in rats. J ournal of Nutrition, 122: 1351-1360.

12. Levenson DI \& Bockman RS (1994). A review of calcium preparation. Nutrition Reviews, 52: 221-232.

13. SAS Institute Inc. SAS/SAT (1985). Guide for Personal Computers. Version 6. SAS Circle, Cary, NC, 183-260.

14. Bogden DJ, Kemp WF, Hans S, Murphy $M$, Fraiman $M$, Czemiach D, Flynn JC, Banua LM, Scimone A, Castrovilly L \& Gertner BS (1995). Dietary calcium and lead interact to modify maternal blood pressure, erythropoiesis and fetal and neonatal growth in rats during pregnancy and lactation. Journal of Nutrition, 125: 990-1002.

15. National Academy of Sciences/National Research Council (1978). Nutrient requirements of the laboratory rat. In: Nutrient Requirements of Laboratory Animals. 3rd edn. National Academy Press, Washington, DC.

16. McCarron DA (1982). Calcium magnesium and phosphorus balance in human and experimental hypertension. Hypertension, 4 (Suppl III): 27-33.

17. McCarron DA (1982). Blood pressure and calcium balance in the Wistar Kyoto rat. Life Sciences, 30: 683-689.

18. Kohno M, Murakawa Kl, Yassunari K, Yokokawa K, Kurihara N \& Takeda T (1989). Possible involvement of atrial natriuretic factor in the antihypertensive action of a high calcium diet in spontaneously hypertensive and Wistar Kyoto rats. Metabolism, 38: 997-1004.

19. Pamnani $M B$, Chen S, Bryant $H J$, Schooley J F \& Haddy FJ (1990). Effect of increased dietary calcium on the development of reduced renal mass saline hypertension in rats. J ournal of the American College of Nutrition, 9: 35-43.

20. Karaki H (1990). The intracellular calciumforce relationship in vascular smooth muscle: time and stimulus dependent dissociation. American J ournal of Hypertension, 3: 253s-256s. 


\section{Brazilian}

Journal of

Medical and

Biological

Research

on the

Internet

\section{Available at}

http://www.epub.org.br/bjmbr/

http://www.scielo.br/ 